\title{
First human experience with autologous Schwann cells to supplement sciatic nerve repair: report of 2 cases with long-term follow-up
}

\author{
Zachary C. Gersey, MS, S. Shelby Burks, MD, Kim D. Anderson, PhD, Marine Dididze, MD, PhD, \\ Aisha Khan, MS, MBA, W. Dalton Dietrich, PhD, and Allan D. Levi, MD, PhD \\ Department of Neurological Surgery and the Miami Project to Cure Paralysis, University of Miami Miller School of Medicine, \\ Miami, Florida
}

\begin{abstract}
OBJECTIVE Long-segment injuries to large peripheral nerves present a challenge to surgeons because insufficient donor tissue limits repair. Multiple supplemental approaches have been investigated, including the use of Schwann cells (SCs). The authors present the first 2 cases using autologous SCs to supplement a peripheral nerve graft repair in humans with long-term follow-up data.
\end{abstract}

METHODS Two patients were enrolled in an FDA-approved trial to assess the safety of using expanded populations of autologous SCs to supplement the repair of long-segment injuries to the sciatic nerve. The mechanism of injury included a boat propeller and a gunshot wound. The SCs were obtained from both the sural nerve and damaged sciatic nerve stump. The SCs were expanded and purified in culture by using heregulin $\beta 1$ and forskolin. Repair was performed with sural nerve grafts, SCs in suspension, and a Duragen graft to house the construct. Follow-up was 36 and 12 months for the patients in Cases 1 and 2, respectively.

RESULTS The patient in Case 1 had a boat propeller injury with complete transection of both sciatic divisions at midthigh. The graft length was approximately $7.5 \mathrm{~cm}$. In the postoperative period the patient regained motor function (Medical Research Council [MRC] Grade 5/5) in the tibial distribution, with partial function in peroneal distribution (MRC Grade $2 / 5$ on dorsiflexion). Partial return of sensory function was also achieved, and neuropathic pain was completely resolved. The patient in Case 2 sustained a gunshot wound to the leg, with partial disruption of the tibial division of the sciatic nerve at the midthigh. The graft length was $5 \mathrm{~cm}$. Postoperatively the patient regained complete motor function of the tibial nerve, with partial return of sensation. Long-term follow-up with both MRI and ultrasound demonstrated nerve graft continuity and the absence of tumor formation at the repair site.

CONCLUSIONS Presented here are the first 2 cases in which autologous SCs were used to supplement human peripheral nerve repair in long-segment injury. Both patients had significant improvement in both motor and sensory function with correlative imaging. This study demonstrates preliminary safety and efficacy of SC transplantation for peripheral nerve repair.

https://thejns.org/doi/abs/10.3171/2016.12.FOCUS16474

KEY WORDS nerve injury; repair; sciatic nerve; sural nerve; Schwann cells; transplantation

$\mathrm{T}$ HE most common source for donor nerve in peripheral nerve grafting is the sural nerve. ${ }^{13,33}$ Unfortunately, in the case of large peripheral nerves the supply of sural nerve autograft can be exhausted quickly. In the case of sciatic nerve injury, the sural nerve is 15 to 20 times smaller in cross-sectional area, and supply will be completely exhausted at $6 \mathrm{~cm}$ of sciatic nerve gap. ${ }^{8}$ The concept of autografting for peripheral nerve injury dates back to the middle portion of the 20th century. ${ }^{36}$ This technique, typically thought of as the gold standard, has shortcomings; namely, lack of graft material, donor site morbidity, and the possible formation of neuroma. Given these

ABBREVIATIONS AGC = axon guidance channel; DN4 = Neuropathic Pain Diagnostic Questionnaire; ISO = International Organization for Standardization; MRC $=$ Medical Research Council; $S C=$ Schwann cell.

ACCOMPANYING EDITORIAL DOI: 10.3171/2016.12.FOCUS16537.

SUBMITTED November 1, 2016. ACCEPTED December 14, 2016.

INCLUDE WHEN CITING DOI: 10.3171/2016.12.FOCUS16474. 
TABLE 1. Characteristics of patients who underwent sciatic nerve repair with SC supplementation

\begin{tabular}{|c|c|c|c|c|c|c|c|c|c|c|c|}
\hline $\begin{array}{l}\text { Case } \\
\text { No. }\end{array}$ & $\begin{array}{l}\text { Age } \\
(\text { yrs }) / \\
\text { Sex }\end{array}$ & $\begin{array}{l}\text { Mechanism } \\
\text { of Injury }\end{array}$ & $\begin{array}{l}\text { Side } \\
\text { of } \\
\text { Injury }\end{array}$ & $\begin{array}{l}\text { Sciatic } \\
\text { Injury } \\
\text { Segment }\end{array}$ & $\begin{array}{l}\text { Complete } \\
\text { Transection }\end{array}$ & $\begin{array}{l}\text { Gap } \\
\text { Length }\end{array}$ & $\begin{array}{l}\text { Sural } \\
\text { Grafts }\end{array}$ & $\begin{array}{l}\text { Dural } \\
\text { Graft }\end{array}$ & $\begin{array}{l}\text { Source } \\
\text { of SCs }\end{array}$ & $\begin{array}{c}\text { SCs Used } \\
\text { (concentration) }\end{array}$ & $\begin{array}{c}\text { Time to } \\
\text { Repair } \\
\text { Postinjury }\end{array}$ \\
\hline 1 & $25 / F$ & $\begin{array}{l}\text { Boat propel- } \\
\text { ler injury }\end{array}$ & Lt & $\begin{array}{l}\text { Upper } \\
\text { thigh }\end{array}$ & Yes & $7.5 \mathrm{~cm}$ & 12 & $\begin{array}{l}\text { Duragen Secure } \\
\text { Dural Regen- } \\
\text { eration Matrix }\end{array}$ & $\begin{array}{l}\text { Sural nerve \& } \\
\text { traumatized } \\
\text { sciatic nerve }\end{array}$ & 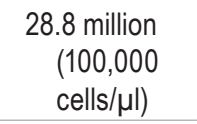 & 30 days \\
\hline 2 & $30 / F$ & $\begin{array}{l}\text { Gunshot } \\
\text { wound }\end{array}$ & Rt & Midthigh & $\begin{array}{c}\text { No, only tibial } \\
\text { component } \\
\text { damaged }\end{array}$ & $5 \mathrm{~cm}$ & 3 & $\begin{array}{l}\text { Duragen Secure } \\
\text { Dural Regen- } \\
\text { eration Matrix }\end{array}$ & Sural nerve & $\begin{array}{c}110 \text { million } \\
(100,000 \\
\text { cells/ul) }\end{array}$ & 41 days \\
\hline
\end{tabular}

limitations, many investigators have worked to develop alternatives to replace or supplement nerve autografting.

One popular alternative to autografts is the use of nerve conduits, or axon guidance channels (AGCs). These are most often applied to very small peripheral nerve injuries with short gaps, because when they are implemented for larger nerve gaps neuroma formation can occur. ${ }^{29}$ The fact that these AGCs are acellular structures is often thought to be the reason they are limited to short, small nerve injuries. In this line of thinking, investigators have looked at various supplemental techniques, including implantation of growth factors or Schwann cells (SCs) into the AGCs. The ability to grow and purify these cells involved major contributions from a basic science perspective. These contributions included the following: 1) isolation of the SCs from adult, human nerve tissue; 2) ability to induce division and growth of the cells once isolated with the use of particular mitogens (heregulin $\beta 1 /$ forskolin), proving that once manipulated and grown in culture the cells could still perform their basic function of promoting axon regeneration and producing myelin; and 3) confirming the safety of these cells and making sure that they did not produce tumorous growths in vivo. ${ }^{10,14,15,19,21,23,24,30,31}$ After this foundation was laid, several studies have shown the ability of SCs to enhance axonal regeneration and improve functional recovery in peripheral nerve injury in mice, rats, and nonhuman primates. ${ }^{3,20,24,25,34}$

In this report we present 2 long-segment (7.5- and $5-\mathrm{cm})$ sciatic nerve injuries where SCs were combined with an autologous nerve construct. These are the first 2 cases in which autologous SCs were transplanted into peripheral nerve injuries in humans (Table 1).

\section{Methods}

\section{Ethical and Legal Approvals}

Approvals from the FDA (expanded access to Investigational New Drug 14856 for one patient and emergency access for the other) and from the University of Miami Miller School of Medicine's institutional review board were obtained for both patients. Patient consent was obtained for supplemental traditional sural nerve graft repair with autologous SCs.

\section{Case Histories}

Case 1

The first patient was a 25-year-old woman who sus- tained multiple lacerating injuries to her left lower extremity due to a boat propeller accident. This caused extensive damage to the left thigh and leg, and the patient was taken emergently to the operating room for control of vascular injuries and debridement of tissue. At the time of initial exploration, complete transection of the sciatic nerve was noted and the damaged nerve ends were sutured to adjacent muscle to prevent retraction. A small $(0.5-\mathrm{cm}) \mathrm{seg}-$ ment of the already damaged sciatic nerve stump was taken for SC harvest and propagation. Three days later the patient underwent repair of her lacerated Achilles tendon, during which a 5-cm segment of sural nerve was taken for autologous SC preparation. The sural nerve had also been previously injured, along with the tendon, by the propeller blade. Prior to sciatic nerve repair and SC transplantation, the patient also underwent anterior quadriceps washout and tendon repair as well as skin grafting of the posterior thigh. The patient ultimately underwent sciatic nerve repair and SC transplantation 30 days after injury and SC harvest.

\section{Case 2}

The second patient was a 30-year-old woman who suffered a gunshot wound to the posterior right midthigh that resulted in bullet fragments being lodged within the sciatic nerve. No initial surgical debridement of the wound was performed, but the patient underwent sural nerve biopsy in which a 5-cm graft was obtained for SC culture. Sciatic nerve repair with autologous SC transplant was performed 29 days after sural nerve harvest of SCs.

\section{Human SC Harvesting and Cell Culture}

Autologous SCs were harvested from a small $(0.5-\mathrm{cm})$ piece of traumatized sciatic nerve at initial debridement and from a 5-cm sural nerve biopsy conducted 3 days after the initial trauma in Case 1. All SCs in Case 2 were harvested from a 5-cm sural nerve biopsy conducted 9 days postinjury. Sural nerve biopsies for both patients were done on the side ipsilateral to the injury. Samples were placed in a Belzer solution, refrigerated at $4{ }^{\circ} \mathrm{C}$, and transported to the cell-manufacturing laboratory (current Good Manufacturing Practices [cGMP] facility) for cell culture. The University of Miami facility consists of a 2500- $\mathrm{ft}^{2}$ area of space under high-efficiency particulate arrestance (HEPA)-filtered air conditioning certified to meet International Organization for Standardization (ISO) Class 7 


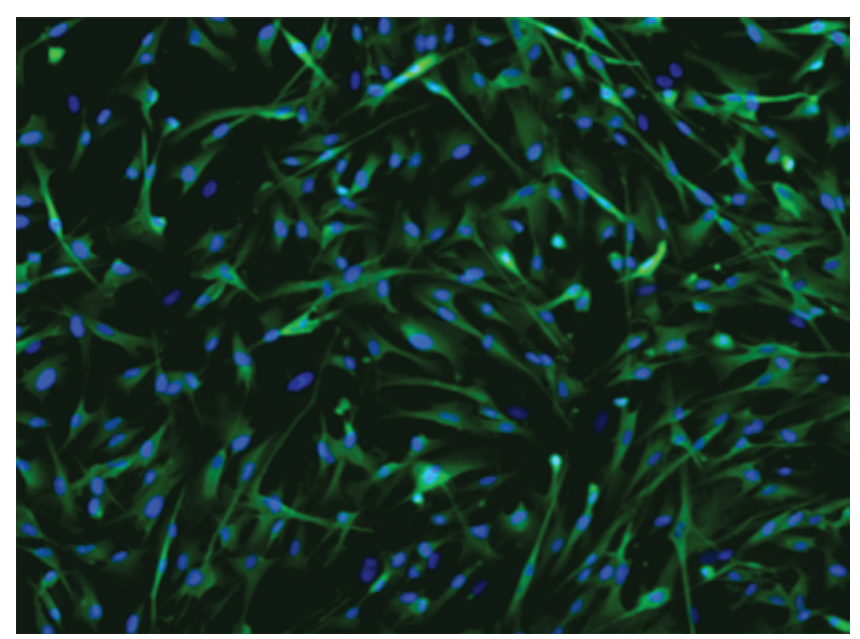

FIG. 1. Photomicrograph showing SC purity after sural nerve harvestdissociation and expansion with mitogens including heregulin $\beta 1$ and forskolin. This demonstrates a high SC purity after S100 immunostaining (green) and addition of the Hoechst agent, which stains all nuclei blue. Nuclei without S100 staining represent fibroblasts. The SC purity is $>95 \%$. Original magnification $\times 20$.

(ISO 14644) standards, and a general laboratory area certified to meet ISO Class 8 standards.

Sural nerve and sciatic nerve biopsy samples were dissected, and fascicles were pulled from epineurium and transferred to a triangular T-75 flask (Corning). The flask was placed in an incubator at $37^{\circ} \mathrm{C}$ with $8 \% \mathrm{CO}_{2}$. Culture medium, which contained 1× DMEM (Life Technologies), $10 \%$ fetal bovine serum (Hyclone, GE Healthcare Life Sciences), $2 \mathrm{mM}$ forskolin (Sigma-Aldrich), $10 \mathrm{nM}$ human recombinant heregulin $\beta 1$ (Genentech), $4 \mathrm{mM} \mathrm{L-}$ glutamine (Life Technologies), and $0.064 \mathrm{mg} / \mathrm{ml}$ gentamicin (APP Pharmaceutical/Fresenius Kabi USA), was changed every other day. On Day 7 for sciatic and Day 5 for sural nerves, the dissociation enzyme solution $(5 \mathrm{ml})$ that contained neutral protease NB (2 DMCU/ml; SERVA Electrophoresis GmbH), collagenase NB 1 (0.5 PZU/ $\mathrm{ml}$; SERVA Electrophoresis $\mathrm{GmbH}$ ) in 1× high-glucose DMEM (Life Technologies) supplemented with $3.1 \mathrm{mM}$ $\mathrm{CaCl}_{2}$ (International Medication Systems Limited) was added to the fascicles and placed inside the incubator at $37^{\circ} \mathrm{C}$ with $8 \% \mathrm{CO}_{2}$ for 18 hours. The fascicles were dissociated, $10 \mathrm{ml} \mathrm{D-10} \mathrm{(Life} \mathrm{Technologies)} \mathrm{was} \mathrm{added} \mathrm{to}$ the flask containing the fascicles, and it was centrifuged at $150 \mathrm{~g}$ for 5 minutes at $4^{\circ} \mathrm{C}$ to pellet the cells. The cells were then washed 2 more times and plated onto mouse laminin-coated plates $\left(1 \mu \mathrm{l} / \mathrm{cm}^{2}\right.$, with a stock concentration of $1 \mathrm{mg} / \mathrm{ml}$; Sigma-Aldrich) using the culture medium. The cells were fed with culture medium every 3 days. After 7 days, cells reached $80 \%$ confluence for the nerve preparations.

For the samples obtained in Case 1, the viable cell count of sural nerve was 19.2 million cells and of the sciatic nerve was 10 million cells. The SC purity assessed by immune staining for sural nerve was $90.2 \%$ and for sciatic nerve it was $97 \%$ (Fig. 1). For samples obtained in Case 2, the viable cell count of sural nerve was 270 million cells. The SC purity assessed by immune staining
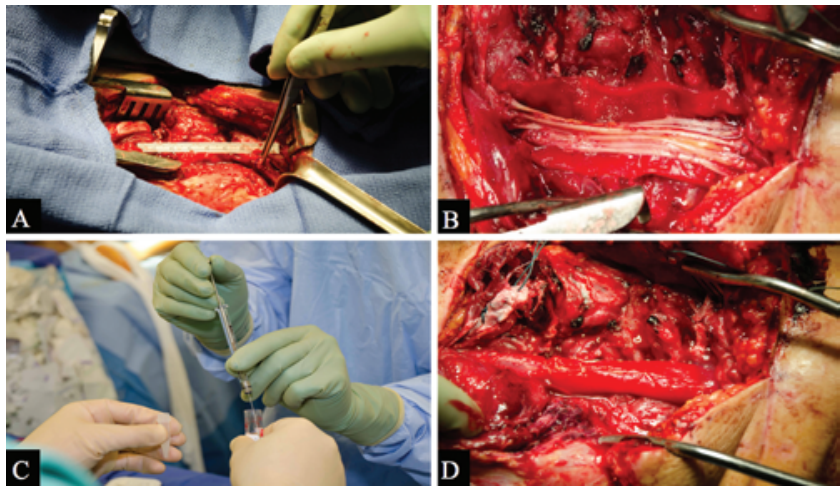

FIG. 2. Case 1. Intraoperative views of sciatic nerve repair with SC transplantation. A: At initial exposure for definitive repair, a 7.5-cm gap between nerve endings was revealed. B: Sural nerve repair with Duragen graft in the background. C: Nerve construct is then supplemented by SCs. D: Duragen graft is sewn around the nerve/SC construct.

for sural nerve was $98.7 \%$. The final cell products were washed 3 times to remove mitogens, laminin, and bovine products. Several controls were used throughout the manufacturing process to ensure that the product was essentially free of process-related contaminants. These controls included the wash steps described above and release testing of the final product. Investigations into the potential related impurities of the manufacturing process had been conducted during process validation studies at the time of our Investigational New Drug submission. The samples were analyzed for residual levels of heregulin $\beta 1$ peptide, mouse laminin, gentamicin, and bovine serum albumin.

The total SC count was 28.8 million at a concentration of 100,000 cells $/ \mu$ with $>99.9 \%$ viability for Case 1 , and 180 million at a concentration of 100,000 cells $/ \mu 1$ with $97.8 \%$ viability for Case 2 . Cells were placed on ice and transported to the operating room for transplantation.

\section{Method of Transplantation}

In Case 1, repair of the sciatic nerve with SC transplantation took place 30 days postinjury. Complete transection of the sciatic nerve was noted at exposure (Fig. 2A). After debridement of scarred nerve ends, the sciatic nerve defect measured $7.5 \mathrm{~cm}$. Bilateral sural nerves were harvested, and $12 \times 7.5-\mathrm{cm}$ nerve grafts were placed and then sutured using 7-0 prolene (Fig. 2B). A total of 28.8 million autologous SCs were supplemented within a Duragen Secure Dural Regeneration Matrix (Duragen; Integra LifeSciences Corp.) (Fig. 2C and D; Video 1).

VIDEO 1. Case 1. Intraoperative video showing sciatic nerve repair with SC supplementation. Copyright Roberto Suazo. Published with permission. Click here to view.

In Case 2, sciatic nerve repair took place 41 days after initial injury and 29 days after sural nerve harvest of SCs. Two bullet fragments were found embedded within the sciatic nerve upon exposure. The bullet fragments were removed from the nerve using microsurgical technique. The tibial and peroneal nerve divisions were separated and intraoperative nerve action potential and ultrasound studies were performed. Results of the nerve action po- 
tential and ultrasound studies demonstrated an intact and functioning peroneal nerve and obvious damage to onethird of the tibial component. Scar tissue was removed and the tibial component was repaired. After removal of scarred nerve ends, the tibial nerve defect measured $5 \mathrm{~cm}$. Sural nerve was obtained and $3 \times 5-\mathrm{cm}$ nerve grafts were placed and then sutured using 7-0 prolene. A total of 110 million autologous SCs of the original 180 million SCs were supplemented within a Duragen Secure Dural Regeneration Matrix.

\section{Postoperative Follow-Up}

Lengths of follow-up were 36 and 12 months for the patients in Cases 1 and 2, respectively. As detailed in Wang et al., patients were serially tested for motor and sensory function according to the Medical Research Council (MRC) grading scale. ${ }^{43}$ Postoperative ultrasound studies were performed to assess continuity of the grafts.

\section{Case Reports \\ Case 1}

At the time of injury and preoperatively, the patient had complete sensory loss to pinprick and light touch without allodynia in the distribution of the sciatic nerve. Motor function was completely lost below the knee (MRC Grade 0/5), hip flexion and knee flexion contracted against gravity (MRC Grade 3/5), and knee extension was active against resistance (MRC Grade 4/5). Pain was maximal postinjury (10/10 according to the Neuropathic Pain Diagnostic Questionnaire [DN4]) ${ }^{4}$ in the distribution of the sciatic nerve. This pattern was consistent with a complete transection of the sciatic nerve at the upper thigh.

There were no postoperative complications with the nerve harvest and sciatic nerve repair within the posterior thigh. The patient did undergo debridement and antibiotic therapy of the anterior thigh for a methicillin-sensitive Staphylococcus aureus infection that occurred after a quadriceps tendon repair. She continued daily exercises and physical therapy postrepair. The patient had neurological assessments at 3-month intervals as well as MRI and ultrasound imaging postoperatively at 6,12 , and 30 months.

Over the course of 36 months the patient's neurological examination results gradually improved. At 15 months there was slight recovery of pinprick and light touch sensation in the distribution of the superficial peroneal nerve, which remained stable at 36 months. No sensation was recovered in the distribution of the sural, deep peroneal, and medial calcaneal nerves. Motor recovery of foot plantar flexion was first noted at 15 months, and at 30 months she achieved full strength recovery (MRC Grade 5/5), which is a definitive sign of regeneration across the sural nerve and autologous SC construct within the tibial division of the sciatic nerve. By the 36-month follow-up, the patient also demonstrated full strength recovery in knee flexion, showed contraction with gravity eliminated (MRC Grade $2 / 5$ ) in foot dorsiflexion and foot eversion, but had no recovery (MRC Grade 0/5) in toe dorsiflexion and foot inversion. Pain gradually diminished over time, and at her 36-month follow she was DN4 0/10 without pain medica- tion and after weaning from gabapentin. She does report occasional lancinating pain in the distribution of the sciatic nerve. Postoperative MRI and ultrasound studies demonstrated continuity of the grafts to both sciatic nerve ends, with no tumor formation. Of note, the patient completed a 5-k run around the time of her 36-month follow-up.

\section{Case 2}

At the time of injury, the patient had no sensation in the sciatic distribution of the right lower extremity. Fortyone days later (preoperatively), the patient had diminished sensation to light touch and pinprick in the sural and superficial peroneal distribution, diminished light touch and no pinprick sensation in the medial calcaneal distribution, and no sensation in the deep peroneal distribution. Preoperatively, motor function was absent (MRC Grade 0/5) in foot eversion and inversion; trace contraction (MRC Grade 1/5) was seen in toe dorsiflexion, foot dorsiflexion, and plantar flexion; knee flexion was contracted against gravity (MRC Grade 3/5); and knee and hip flexion were at full strength (MRC Grade 5/5). Postinjury, the patient noted DN4 10/10 sharp pain in the distribution of the sciatic nerve, which improved to DN4 8/10 immediately prior to the nerve repair. Examination and imaging findings were consistent with damage to the sciatic nerve at the midthigh (Fig. 3).

There were no postoperative complications with the sciatic nerve repair and SC transplantation. The patient had neurological assessments at 3-month intervals as well as MRI at 4 months and ultrasound at 12 months.

Over the course of 12 months the results of the patient's neurological examination gradually improved. At 12-month follow-up there was significant improvement in toe dorsiflexion (MRC Grade 4/5), foot plantar flexion (MRC Grade 5/5), and inversion (MRC Grade 4/5). Complete restoration in motor strength demonstrates the efficacy of sciatic nerve repair with supplementation of SCs. Pain gradually improved over the course of followup visits in both distribution and intensity. At 3 months the distribution only involved the lateral leg and foot, and subsequently only the foot at 12-month follow-up. Intensity decreased to DN4 3/10 at her 12-month follow-up visit. The MRI and ultrasound studies demonstrated continuity of the grafts to both sciatic nerve ends, with no tumor formation.

\section{Discussion}

Sciatic nerve injuries are relatively rare, yet they are some of the most challenging cases a peripheral nerve surgeon will face. ${ }^{2}$ Damage to the sciatic nerve can occur through a variety of means. Iatrogenic causes such as intragluteal injections and hip joint repair, as well as hip fractures or dislocations and penetrating trauma commonly injure the upper sciatic nerve. Stab wounds, gunshot wounds, and boat propeller injuries are commonly associated with midsciatic injury. ${ }^{8,22}$ Injury location and sciatic division have been associated with differing rates of success after nerve autograft repair. High sciatic injuries involving the peroneal component have been associated with poor outcomes, whereas midthigh injuries to the tibi- 


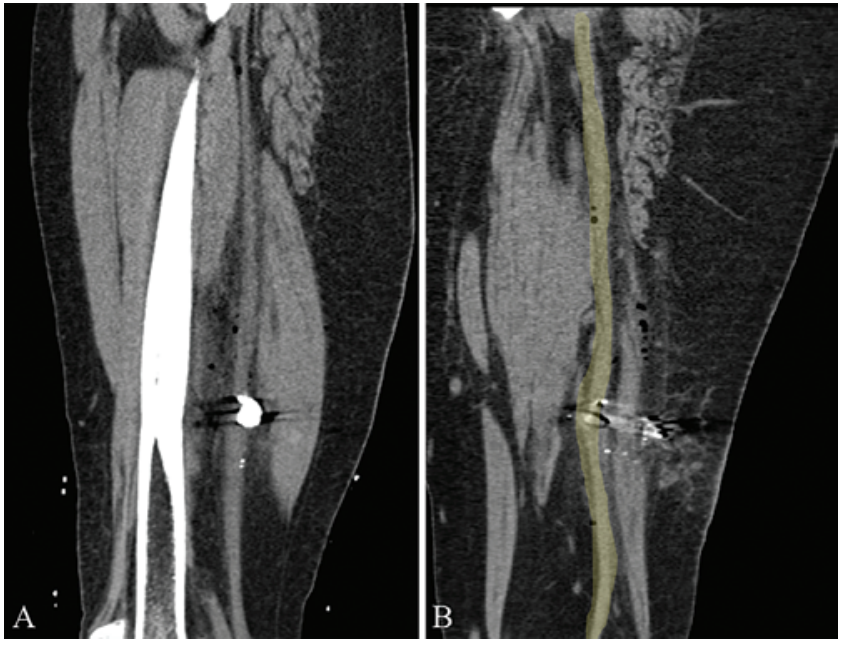

FIG. 3. Case 2. Computed tomographic scans of the right thigh of the patient at time of injury. A: Sagittal image showing bullet lodged in the sciatic nerve. B: Coronal image showing bullet lodged in sciatic nerve (yellow).

al component have had higher rates of success. ${ }^{2,32,35}$ Along with location and sciatic division, nerve gaps $>5 \mathrm{~cm}$ have been associated with worse outcomes. ${ }^{35}$

Repair of a damaged sciatic nerve that has a significant gap is particularly challenging due to several factors. Sural nerves, the most common donor autograft, are typically insufficient in length due to the large discrepancy in crosssectional area between donor and sciatic nerve. Patients with thin sural nerves may only be able to cover a $2.5-\mathrm{cm}$ gap. ${ }^{8}$ In addition to insufficient graft material, sensory loss at the donor site and possible neuroma formation are possible morbidities associated with autologous sensory nerve graft transplants. ${ }^{36}$ Although we do not report a control of sural graft alone in this patient series, historical data from Roganovic et al. demonstrate that worse outcomes started with nerve defects $>5 \mathrm{~cm}$ in patients with injuries to the tibial nerve or tibial division of the sciatic nerve who were treated with sural nerve grafts or nerve grafts from other sources alone. ${ }^{35}$ Although a larger sample size is necessary, here we demonstrate good outcomes in 2 patients with nerve gaps $\geq 5 \mathrm{~cm}$ by using sural nerve grafts supplemented with autologous SCs.

Recent data suggest that the use of AGCs may be an alternative to repairing nerve gaps. Although initial reports focused on short gap repairs, ${ }^{5,18,26}$ several substrates have been studied for their potential to heal large gap defects when supplemented with AGCs, including purified SCs. ${ }^{1,6}$, $7,9,11,12,16,17,27,28,34,37,38,40-42,44$ Berrocal et al. demonstrated that adding autologous SCs suspended in serum to AGCs significantly enhanced the ability to bridge larger gap distances in sciatic nerve repair in rats. ${ }^{3}$

Autologous SCs can be harvested from either a donor nerve or from the epicenter of the traumatized nerve ends in sharp injuries (propeller injury, gunshot wound, stab wound). Harvesting SCs from donor nerves requires sacrifice of sensory donor nerves, which may lead to future morbidity, whereas harvesting from the traumatized nerve ends will lead to no deficit because these ends will eventu- ally scar and be sacrificed by the surgeon. In this study, SCs from the patient in Case 1 were harvested from both a donor nerve and the traumatized nerve, whereas SCs from the patient in Case 2 were only harvested from a donor sural nerve. Both methods provided sufficient samples to propagate SCs in culture until the time of surgery (30 days for Case 1 and 29 days for Case 2).

Presented here are the first 2 cases treated using autologous SCs to supplement human peripheral nerve repair in long-segment injury. Both patients had significant improvement in both motor and sensory function, with correlative imaging, after large-gap $(>5 \mathrm{~cm})$ injuries generally associated with poor functional recovery. ${ }^{35}$ Near complete resolution and significant improvement in pain symptoms in the patients in Cases 1 and 2, respectively, were observed-an outcome rarely seen in autologous nerve grafting. A proposed mechanism for pain reduction in entubulation strategies is that AGCs provide a scaffold for more directional growth of axons and less growth of pain fibers. ${ }^{39}$ In these cases a Duragen wrapping was used and may have assisted in the procedure's success. Donor SCs were able to propagate to sufficient amounts for transplantation in both patients far earlier than 4 months, when poor outcomes are seen. ${ }^{35}$ Grafts remained in continuity and no neuromas or tumors were seen at 12 and 36 months.

Although this study demonstrates preliminary safety and efficacy of SC transplantation for peripheral nerve repair in humans, obvious limitations and concerns must be addressed. First, even though outcomes were excellent and complications were minimal in our 2 initial patients, the sample size must be increased and randomization must be introduced in future studies to fully determine effects. A potential safety concern associated with cellular autotransplantation for peripheral nerve repair is the possibility of creating tumors. Although neither patient developed any evidence of tumor formation at 12 and 36 months, respectively, long-term monitoring is essential and ongoing.

\section{Conclusions}

This study is the first long-term follow-up in the first 2 human cases of autologous SC transplants for peripheral nerve repair. These data are evidence that autologous SCs may be a viable option for long-gap nerve defect repairs. Future directions will focus on improved delivery methods of SCs to injured areas, minimization or elimination of sural nerve grafts, and optimization of autologous SC culture methods.

\section{Acknowledgments}

We thank Roberto Suazo for filming the supplementary intraoperative video and capturing intraoperative photographs.

\section{References}

1. Ansselin AD, Fink T, Davey DF: Peripheral nerve regeneration through nerve guides seeded with adult Schwann cells. Neuropathol Appl Neurobiol 23:387-398, 1997

2. Aydin A, Ozkan T, Aydin HU, Topalan M, Erer M, Ozkan S, et al: The results of surgical repair of sciatic nerve injuries. Acta Orthop Traumatol Turc 44:48-53, 2010 
3. Berrocal YA, Almeida VW, Gupta R, Levi AD: Transplantation of Schwann cells in a collagen tube for the repair of large, segmental peripheral nerve defects in rats. J Neurosurg 119:720-732, 2013

4. Bouhassira D, Attal N, Alchaar H, Boureau F, Brochet B, Bruxelle J, et al: Comparison of pain syndromes associated with nervous or somatic lesions and development of a new neuropathic pain diagnostic questionnaire (DN4). Pain 114:29-36, 2005

5. Brooks DN, Weber RV, Chao JD, Rinker BD, Zoldos J, Robichaux MR, et al: Processed nerve allografts for peripheral nerve reconstruction: a multicenter study of utilization and outcomes in sensory, mixed, and motor nerve reconstructions. Microsurgery 32:1-14, 2012

6. Bryan DJ, Holway AH, Wang KK, Silva AE, Trantolo DJ, Wise D, et al: Influence of glial growth factor and Schwann cells in a bioresorbable guidance channel on peripheral nerve regeneration. Tissue Eng 6:129-138, 2000

7. Burkhanov AI, Nosova LI, Baĭgutanov ZhB: [Adaptation of students to training in institutes of higher education.] Gig Sanit (7-8):53-55, 1992 (Russian)

8. Burks SS, Levi DJ, Hayes S, Levi AD: Challenges in sciatic nerve repair: anatomical considerations. J Neurosurg 121:210-218, 2014

9. Cameron M: Family care nursing at Sturt CAE. Australas Nurses J 5:59-60, 1976

10. Casella GT, Bunge RP, Wood PM: Improved method for harvesting human Schwann cells from mature peripheral nerve and expansion in vitro. Glia 17:327-338, 1996

11. Cheng B, Chen Z: Fabricating autologous tissue to engineer artificial nerve. Microsurgery 22:133-137, 2002

12. Couturier CA, Dauge MC, Henin D, Alnot JY, Masmejean EH: Nerve repair using a composite graft of vein and denatured skeletal muscle: morphologic analysis. J Reconstr Microsurg 18:681-688, 2002

13. Dellon AL, Mackinnon SE: An alternative to the classical nerve graft for the management of the short nerve gap. Plast Reconstr Surg 82:849-856, 1988

14. Emery E, Li X, Brunschwig JP, Olson L, Levi AD: Assessment of the malignant potential of mitogen stimulated human Schwann cells. J Peripher Nerv Syst 4:107-116, 1999

15. Evans PJ, Mackinnon SE, Levi AD, Wade JA, Hunter DA, Nakao Y, et al: Cold preserved nerve allografts: changes in basement membrane, viability, immunogenicity, and regeneration. Muscle Nerve 21:1507-1522, 1998

16. Fansa H, Dodic T, Wolf G, Schneider W, Keilhoff G: Tissue engineering of peripheral nerves: epineurial grafts with application of cultured Schwann cells. Microsurgery 23:72-77, 2003

17. Gravvanis AI, Tsoutsos DA, Tagaris GA, Papalois AE, Patralexis CG, Iconomou TG, et al: Beneficial effect of nerve growth factor-7S on peripheral nerve regeneration through inside-out vein grafts: an experimental study. Microsurgery 24:408-415, 2004

18. Karabekmez FE, Duymaz A, Moran SL: Early clinical outcomes with the use of decellularized nerve allograft for repair of sensory defects within the hand. Hand (NY) 4:245249, 2009

19. Levi AD: Characterization of the technique involved in isolating Schwann cells from adult human peripheral nerve. J Neurosci Methods 68:21-26, 1996

20. Levi AD, Bunge RP: Studies of myelin formation after transplantation of human Schwann cells into the severe combined immunodeficient mouse. Exp Neurol 130:41-52, 1994

21. Levi AD, Bunge RP, Lofgren JA, Meima L, Hefti F, Nikolics $\mathrm{K}$, et al: The influence of heregulins on human Schwann cell proliferation. J Neurosci 15:1329-1340, 1995

22. Levi AD, Burks SS, Anderson KD, Dididze M, Khan A, Dietrich WD: The use of autologous Schwann cells to supple- ment sciatic nerve repair with a large gap: first in human experience. Cell Transplant 25:1395-1403, 2016

23. Levi AD, Evans PJ, Mackinnon SE, Bunge RP: Cold storage of peripheral nerves: an in vitro assay of cell viability and function. Glia 10:121-131, 1994

24. Levi AD, Guénard V, Aebischer P, Bunge RP: The functional characteristics of Schwann cells cultured from human peripheral nerve after transplantation into a gap within the rat sciatic nerve. J Neurosci 14:1309-1319, 1994

25. Levi AD, Sonntag VK, Dickman C, Mather J, Li RH, Cordoba SC, et al: The role of cultured Schwann cell grafts in the repair of gaps within the peripheral nervous system of primates. Exp Neurol 143:25-36, 1997

26. Lundborg G, Rosén B, Dahlin L, Danielsen N, Holmberg $\mathrm{J}$ : Tubular versus conventional repair of median and ulnar nerves in the human forearm: early results from a prospective, randomized, clinical study. J Hand Surg Am 22:99_ 106, 1997

27. Meek MF, Robinson PH, Stokroos I, Blaauw EH, Kors G, den Dunnen WF: Electronmicroscopical evaluation of shortterm nerve regeneration through a thin-walled biodegradable poly(DLLA- $\varepsilon-C L)$ nerve guide filled with modified denatured muscle tissue. Biomaterials 22:1177-1185, 2001

28. Mligiliche NL, Tabata Y, Kitada M, Endoh K, Okamato K, Fujimoto E, et al: Poly lactic acid-caprolactone copolymer tube with a denatured skeletal muscle segment inside as a guide for peripheral nerve regeneration: a morphological and electrophysiological evaluation of the regenerated nerves. Anat Sci Int 78:156-161, 2003

29. Moore AM, Kasukurthi R, Magill CK, Farhadi HF, Borschel GH, Mackinnon SE: Limitations of conduits in peripheral nerve repairs. Hand (NY) 4:180-186, 2009

30. Morrissey TK, Kleitman N, Bunge RP: Isolation and functional characterization of Schwann cells derived from adult peripheral nerve. J Neurosci 11:2433-2442, 1991

31. Morrissey TK, Levi AD, Nuijens A, Sliwkowski MX, Bunge RP: Axon-induced mitogenesis of human Schwann cells involves heregulin and p185erbB2. Proc Natl Acad Sci U S A 92:1431-1435, 1995

32. Murovic JA: Lower-extremity peripheral nerve injuries: a Louisiana State University Health Sciences Center literature review with comparison of the operative outcomes of 806 Louisiana State University Health Sciences Center sciatic, common peroneal, and tibial nerve lesions. Neurosurgery 65 (4 Suppl):A18-A23, 2009

33. Riedl O, Frey M: Anatomy of the sural nerve: cadaver study and literature review. Plast Reconstr Surg 131:802-810, 2013

34. Rodríguez FJ, Verdú E, Ceballos D, Navarro X: Nerve guides seeded with autologous Schwann cells improve nerve regeneration. Exp Neurol 161:571-584, 2000

35. Roganović Z, Pavlićević G, Petković S: Missile-induced complete lesions of the tibial nerve and tibial division of the sciatic nerve: results of 119 repairs. J Neurosurg 103:622-629, 2005

36. Seddon HJ: The use of autogenous grafts for the repair of large gaps in peripheral nerves. Br J Surg 35:151-167, 1947

37. Strauch B, Rodriguez DM, Diaz J, Yu HL, Kaplan G, Weinstein DE: Autologous Schwann cells drive regeneration through a 6-cm autogenous venous nerve conduit. J Reconstr Microsurg 17:589-597, 2001

38. Terris DJ, Toft KM, Moir M, Lum J, Wang M: Brain-derived neurotrophic factor-enriched collagen tubule as a substitute for autologous nerve grafts. Arch Otolaryngol Head Neck Surg 127:294-298, 2001

39. Tyner TR, Parks N, Faria S, Simons M, Stapp B, Curtis B, et al: Effects of collagen nerve guide on neuroma formation and neuropathic pain in a rat model. Am J Surg 193:e1-e6, 2007

40. Varejão AS, Cabrita AM, Geuna S, Patrício JA, Azevedo HR, 
Ferreira AJ, et al: Functional assessment of sciatic nerve recovery: biodegradable poly (DLLA- $\varepsilon-C L$ ) nerve guide filled with fresh skeletal muscle. Microsurgery 23:346-353, 2003

41. Varejão AS, Cabrita AM, Meek MF, Fornaro M, Geuna S: Nerve regeneration inside fresh skeletal muscle-enriched synthetic tubes: a laser confocal microscope study in the rat sciatic nerve model. Ital J Anat Embryol 108:77-82, 2003

42. Varejão AS, Cabrita AM, Meek MF, Fornaro M, Geuna S, Giacobini-Robecchi MG: Morphology of nerve fiber regeneration along a biodegradable poly (DLLA- $\varepsilon-C L)$ nerve guide filled with fresh skeletal muscle. Microsurgery 23:338-345, 2003

43. Wang Y, Sunitha M, Chung KC: How to measure outcomes of peripheral nerve surgery. Hand Clin 29:349-361, 2013

44. Zhang F, Blain B, Beck J, Zhang J, Chen Z, Chen ZW, et al: Autogenous venous graft with one-stage prepared Schwann cells as a conduit for repair of long segmental nerve defects. J Reconstr Microsurg 18:295-300, 2002

\section{Disclosures}

Dr. Anderson is a consultant for Vertex, Inc. Dr. Levi has received a teaching honorarium from Medtronic and grant support from the US Department of Defense.

\section{Author Contributions}

Conception and design: all authors. Acquisition of data: Levi, Gersey, Burks, Dididze, Khan, Dietrich. Analysis and interpretation of data: Levi, Burks, Anderson, Dididze, Khan, Dietrich. Drafting the article: Levi, Gersey, Burks, Anderson, Dietrich. Critically revising the article: Levi, Burks, Anderson, Dididze, Khan, Dietrich. Reviewed submitted version of manuscript: all authors. Approved the final version of the manuscript on behalf of all authors: Levi. Statistical analysis: Anderson, Dietrich. Administrative/technical/material support: Levi, Burks, Khan. Study supervision: Levi.

\section{Supplemental Information \\ Videos}

Video 1. https://vimeo.com/198342732.

\section{Correspondence}

Allan D. Levi, Department of Neurological Surgery, Lois Pope LIFE Center, 2nd Fl., 1095 NW 14th Terrace (D4-6), Miami, FL 33136. email: alevi@med.miami.edu. 